\title{
Charging Tendency of Phosphors and Blackening Phenomena in Fluorescent Lamps
}

\author{
Hidenori ITO, Yoji YUGE and Akira TAYA \\ Toshiba Lighting \& Technology Corporation \\ 1-201-1 Funakoshi-cho, Yokosuka-shi, Kanagawa 237, JAPAN \\ Masaaki TAMATANI \\ R \& D Center, Toshiba Corporatiion \\ 1 Komukai Toshiba-cho, Saiwai-ku Kawasaki-shi, Kanagawa 210, JAPAN
}

\section{Kenji TERASHIMA}

Electron Devices Division, Toshiba Corporation

72 Horikawa-cho, Saiwai-ku Kawasaki-shi, Kanagawa 210, JAPAN

Paper originally published in Japanese in J. IEIJ, Vol. 76, No. 10, 1992

\begin{abstract}
Long-term lumen maintenance of high-load fluorescent lamps is investigated using 3-band rare earth phosphors. The contact electric charging tendency of the phosphor is systematically varied by depositing colloids on the phosphor particle surfaces. For every phosphor system tested, the maintenance shows a maximum at a certain value in the charging tendency where the amount of mercury oxide adsorbed on the phosphor is minimum. On the other hand, the depreciation of the phosphors themselves does not depend on the charging tendency. Furthermore, the charging tendency of mercury oxide exists near that for maximum maintenance. From these results, it is concluded that the difference in charging tendency between mercury oxide and a phosphor governs mercury oxide adsorption on the phosphor; the amount of adsorbed mercury oxide becomes larger with an increase in the difference causing significant lamp depreciation.
\end{abstract}

\section{Introduction}

Luminous flux of a fluorescent lamp is depreciated with cumulation of operating time. The depreciation of the luminous flux is caused by several factors. First, phosphors themselves are degraded. A calcium halophosphate phosphor, for example, is colored and degraded as color centers are formed under vacuum ultraviolet rays $(185 \mathrm{~nm}$ rays of mercury) irradiation in a lamp ${ }^{1)}$. For zinc silicate phosphors, the crystal structure of particle surfaces is damaged by gaseous ion bombardment in a lamp, resulting in the degradation of the phosphors ${ }^{2}$. Three-band blend phosphors composed of rare earth compounds, on the contrary, evade the influence of the ultraviolet rays and ions ${ }^{3)}$, and accordingly, they are now in wide use in compact-type fluorescent lamps, for example.
Even when rare earth phosphors are used, coloring materials such as mercury and mercury oxide are adsorbed on these phosphors and depreciate their luminous flux ${ }^{2), 4), 5}$. This is another cause of the depreciation of the luminous flux in addition to the degradation of phosphors themselves. To cope with the adsorption, a variety of measures, including inorganic thin film coating on the inner surface wall of the lamp, has been put to practical use ${ }^{6}$. Further, it is known that the adsorption amount varies depending on types of phosphors ${ }^{7}$. However, no studies have been done using systematic variation in phosphor properties to determine the relationship between phosphor properties and adsorption amount. Thus, the reason why the adsorption amount varies depending on types of phosphors, has not been found. 
We assumed that the adsorption ability of mercury and its compounds on phosphors may result from difference in contact charging tendency between these materials. Generally, when two dissimilar materials make contact with each other, positive and negative electric charges are generated on the surfaces of each material. This phenomenon is called contact charging (or electrification). Tables of contact (or frictional) charging series are known, which arrange materials positive charged at upper positions and materials negative charged in lower ${ }^{s)}$. It is said that the upper position a material is listed at, the more intensively it is positive charged, and that the lower position a material is listed at, the more intensively it is negative charged. Recently, it has become possible to measure quantitatively the amount of the contact electric charging for powders using such an equipment as the blow-off apparatus. Charging tendency for simple inorganic compounds has been investigated by measuring charge amount against a certain reference material ${ }^{9)}$. This investigation shows that the charge amount generated between two dissimilar materials becomes larger with increase in the difference in charging tendency between them. Therefore, the greater the difference in charging tendency between these two materials is, the larger the electrostatic attractive force exerted between them is as well. Moreover, it shows that metal oxides with more acidity tend to be negative charged; those with more basicity tend to be positive charged. Mercury oxide $(\mathrm{HgO})$, which is supposed to be formed through a reaction of mercury atoms and oxygen in a lamp, has almost the same positive charging tendency as $\mathrm{Y}_{2} \mathrm{O}_{3}$ and $\mathrm{Al}_{2} \mathrm{O}_{3}$. It is also known that the charging tendency varies depending on types of phosphors ${ }^{10), 11}$.

The present paper aims to find influences of phosphor charging tendency on the depreciation of the lamp luminous flux and on the amount of mercury adsorbed experimentally, and to check if the influences result from the difference in charging tendency between a phosphor and blackened materials. Causes of luminous flux depreciation include the degradation of phosphors themselves, and presently available methods give only poor correctness for determining charging tendency for phosphors having different particle sizes. Therefore, it is difficult to extract only the influence of charging tendency from the comparison of lumen maintenance data for lamps using commercially available phosphors. For this reason, charging tendency of a phosphor was varied systematically by surface treatments, and the influence of charging tendency was investigated in the respective phosphor material system.

\section{Experiments}

\subsection{Methods for controlling phosphor charging tendency}

Three components of a 3-band rare earth blend phosphor (made by Toshiba Corp.) were used for phosphors to be tested; $\mathrm{Y}_{2} \mathrm{O}_{3}$ : Eu (the red-emitting component), La $(\mathrm{P}, \mathrm{Si}) \mathrm{O}_{4}: \mathrm{Ce}, \mathrm{Tb}$ (the green-emitting component), and $\mathrm{BaMg}_{2} \mathrm{Al}_{16} \mathrm{O}_{27}:$ Eu (the blue-emitting component). A conventional phosphor, $\mathrm{Zn}_{2} \mathrm{SiO}_{4}: \mathrm{Mn}$, was also used.

In order to vary charging tendency of a phosphor in a wider range than that determined depending on types of phosphors, metal oxide colloid fine particles having characteristic charging tendency were deposited on the phosphor particle surfaces. Charging tendency of a phosphor was controlled by varying types of the colloid and the amount of deposition. $\mathrm{MgO}$ and $\mathrm{ZnO}$, both of which tend to be positive charged, and $\mathrm{SiO}_{2}$, which tends to be negative charged, were chosen for the colloids" $s^{9}$. The $\mathrm{MgO}$ was Baikalox M120 from Baikowsky Corp. and the $\mathrm{SiO}_{2}$ was OX-50 from Nippon Aerosil Company. The $\mathrm{ZnO}$ was a precipitate obtained from aqueous solution reaction. The colloids were deposited on phosphor particles as follows. A colloid aqueous suspension was added to a phosphor aqueous suspension, and the resultant mixture was stirred. Subsequently, phosphor particles were separated from solution by vacuum-filtering, and dried at a temperature above $125^{\circ} \mathrm{C}$ for 16 hours. In order to avoid a possibility that a part of the colloid had turned to hydroxide in the suspension, the dried phosphor was further fired in air at $350^{\circ} \mathrm{C}$ for 5 hours, where hydroxide is considered to turn to oxide ${ }^{12)}$. Obtained phosphors were passed through a 200 -mesh. nylon screen.

Fig. 1 is SEM photographs showing colloids deposited on a $\mathrm{Y}_{2} \mathrm{O}_{3}$ : Eu phosphor. $\mathrm{MgO}$ and $\mathrm{SiO}_{2}$ colloids with approximately $0.2 \mu \mathrm{m}$ size are well dispersed and deposited on the phosphor particle surfaces. In the case

Table 1 Samples

\begin{tabular}{|c|c|c|c|c|c|}
\hline $\begin{array}{c}\text { Sample } \\
\text { No. }\end{array}$ & Phosphor & $\begin{array}{r}\text { Colloid } \\
\text { amo }\end{array}$ & $\begin{array}{l}\text { osition } \\
(\%)\end{array}$ & $\begin{array}{c}\text { Particle size } \\
(\mu \mathrm{m})\end{array}$ & $\begin{array}{l}\text { Phosphor (\%) } \\
\text { brightness ratio }\end{array}$ \\
\hline $\mathrm{R}-0$ & Red & - & - & 4.1 & 100.0 \\
\hline$R-1$ & $"$ & $\mathrm{MgO}$ & 0.2 & 3.8 & 100.0 \\
\hline $\mathrm{R}-2$ & " & $\mathrm{SiO}_{2}$ & 0.2 & 3.9 & 99.6 \\
\hline $\mathrm{R}-3$ & $"$ & $\mathrm{SiO}_{2}$ & 0.5 & 3.8 & 100.0 \\
\hline$R-4$ & " & $\mathrm{SiO}_{2}$ & 1.0 & 3.6 & 101.8 \\
\hline$R-26$ & $n$ & $\mathrm{MgO}$ & 0.1 & 4.0 & 100.0 \\
\hline $\mathrm{R}-27$ & $"$ & $\mathrm{MgO}$ & 0.05 & 4.0 & 100.0 \\
\hline$R-28$ & $n$ & $\mathrm{SiO}_{2}$ & 0.05 & - & 101.2 \\
\hline$G-0$ & Green & - & - & 4.3 & 100.0 \\
\hline$G-1$ & " & $\mathrm{MgO}$ & 0.2 & 4.2 & 100.5 \\
\hline$G-2$ & $n$ & $\mathrm{SiO}_{2}$ & 1.0 & 4.1 & 104.7 \\
\hline$G-01$ & $"$ & $\mathrm{SiO}_{2}$ & 0.30 & 4.3 & 101.0 \\
\hline$G-02$ & $n$ & $\mathrm{SiO}_{2}$ & 0.44 & 4.2 & 101.5 \\
\hline$B-0$ & Blue & - & - & 4.2 & 100.0 \\
\hline$B-1$ & $n$ & $\mathrm{MgO}$ & 0.2 & 4.1 & 98.8 \\
\hline$B-2$ & $n$ & $\mathrm{SiO}_{2}$ & 0.3 & 4.1 & 98.1 \\
\hline $\mathrm{B}-01$ & $"$ & $\mathrm{MgO}$ & 0.55 & 4.1 & 99.0 \\
\hline B -02 & $"$ & $\mathrm{MgO}$ & 0.07 & 4.2 & 100.1 \\
\hline$B-03$ & $"$ & $\mathrm{MgO}$ & 0.04 & 4.2 & 100.0 \\
\hline
\end{tabular}




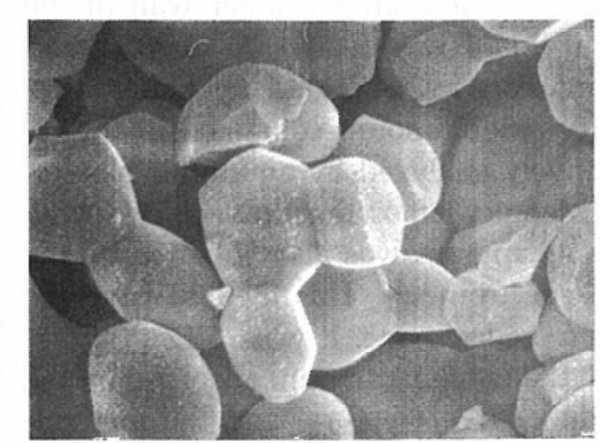

No colloid deposition

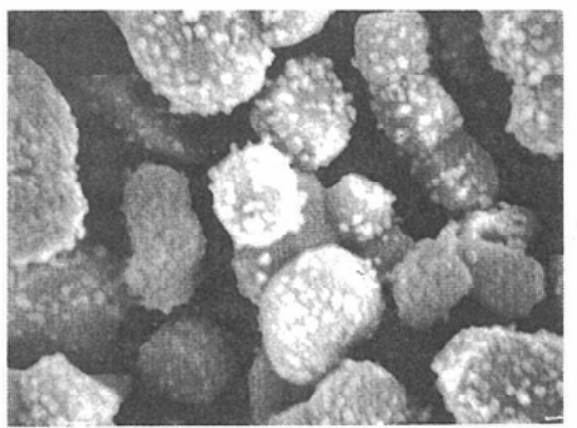

$0.5 \% \mathrm{SiO}_{2}$ colloid deposition

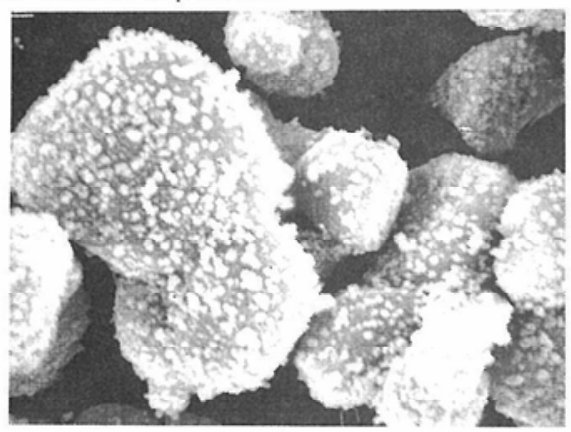

$1.0 \% \mathrm{SiO}_{2}$ colloid deposition

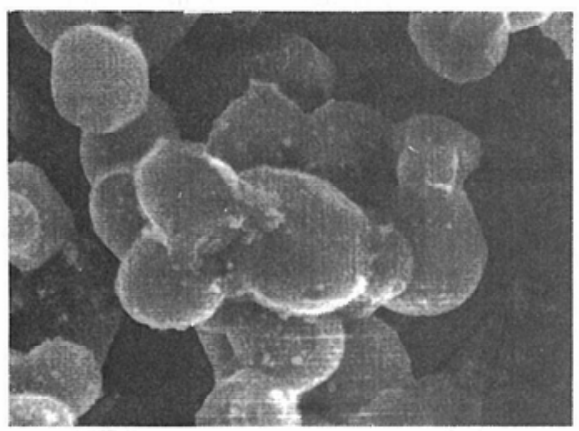

$0.2 \% \mathrm{SiO}_{2}$ colloid deposition

Fig. 1 SEM photographs of phosphors $\left(\mathrm{Y}_{2} \mathrm{O}_{3}\right.$ : Eu) after colloid deposition treatments.

of other phosphors also, it was confirmed that colloid particles were well dispersed and deposited on their surfaces. Table 1 shows the amount of colloid deposited, average phosphor particle size obtained with the air permeability method ${ }^{13)}$, and relative brightness under $254 \mathrm{~nm}$ ultraviolet ray excitation. Phosphor brightness was hardly varied by the colloid treatments.

Charging tendency of a phosphor (sample) powder was obtained as the charge amount against a reduced iron (carrier) powder measured using the blow-off apparatus shown in Fig. $\mathbf{2}^{7}$. The procedure of the measurement is as follows. Sample and carrier were blended in a polyethylene bottle and a certain amount of the mixture was placed on the stainless steel mesh filter attached to the

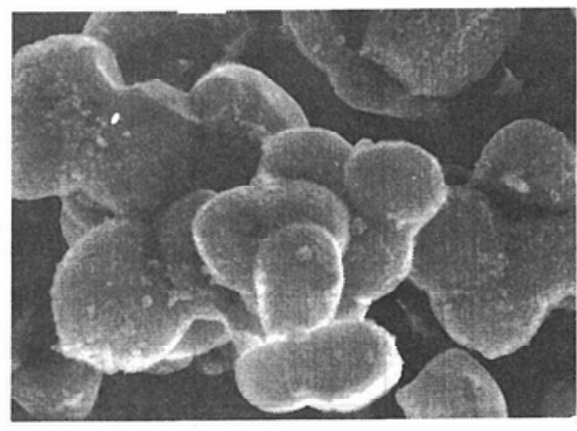

$0.2 \% \mathrm{MgO}$ colloid deposition

Faraday cage in the apparatus. Size of openings of the mesh was larger and smaller than the sample and carrier size, respectively. Compressed nitrogen gas spurted from the upper nozzle of the cage and blew only sample powder out of the cage through the mesh. Carrier particles left in the cage had charges of an amount equal to and a polarity opposite to those on the sample blown off. Then, the charges left in the cage were measured with a capacitor and an electrometer connected to the cage.

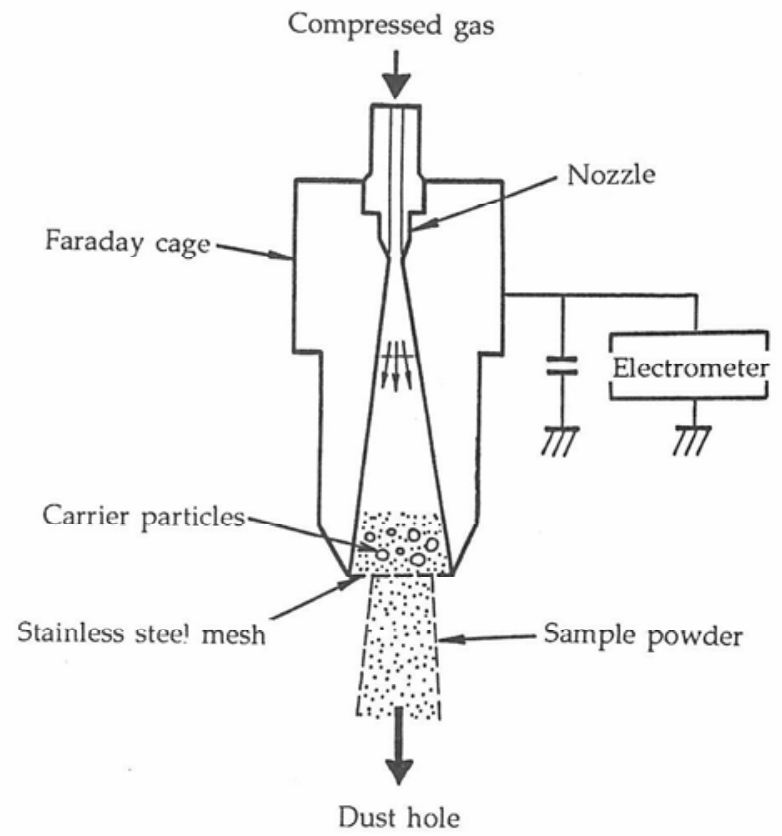

Fig. 2 Blow-off charge measuring apparatus ${ }^{7}$.

Fig. 3 shows the charging tendency for various samples. The charging tendency is expressed as the charge amount $(\mu \mathrm{C})$ per $1 \mathrm{~g}$ sample generated when the reduced 


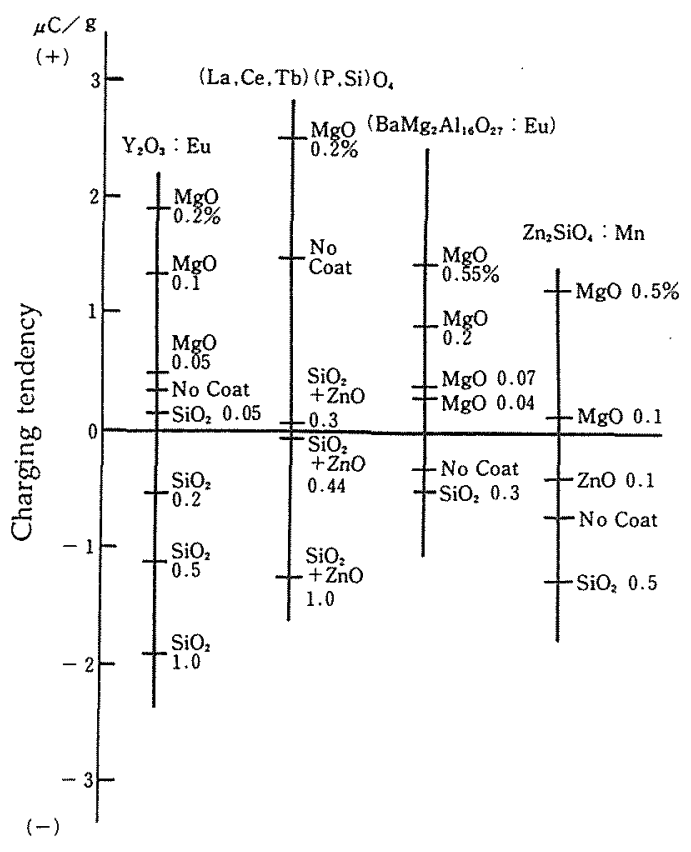

Fig. 3 Charging tendency of colloid deposited phosphors.

iron powder was used as the carrier. Both of $\mathrm{MgO}$ and $\mathrm{ZnO}$ colloid depositions shift phosphor charging tendency to the positive direction, and $\mathrm{SiO}_{2}$ to the negative.

\subsection{Lamp testing}

Inner wall of a straight glass tube with $10 \mathrm{~mm}$ inner diameter and $300 \mathrm{~mm}$ distance between two electrodes, was coated with a charging-tendency-controlled sample phosphor to be tested. A phosphor was dispersed in a butyl-acetate solution containing a small amount of inorganic binder and nitrocellulose. Viscosity of the suspension was adjusted so as to obtain a certain thickness of the phosphor screen layer formed. The phosphor screen was baked at $550^{\circ} \mathrm{C}$ for 10 minutes. The tube was filled with mercury metal and Ar gas of a pressure of $479 \mathrm{~Pa}$. The lamp was so designed that all the excess mercury could condense in a capillary attached to the edge of the lamp, the coolest spot when the lamp was on. During lamp operation, bulb temperature was about $80^{\circ} \mathrm{C}$; lamp current was $0.28 \mathrm{~A}$; lamp power was about $14 \mathrm{~W}$; and inner wall load was about $0.15 \mathrm{~W} / \mathrm{cm}^{2}$.

Before the lamp life tests, difference in the total light flux was small at within $2 \%$ between lamps coated with a colloid-treated phosphor and a non-treated phosphor.

\subsection{Chemical analysis for mercury and mercury oxide}

A test lamp tube was cut at its edge and a phosphor screen was recovered as a suspension solution by wash- ing it out with acetic acid from the inner wall of the lamp. The resultant liquid was heated up to $90^{\circ} \mathrm{C}$, and subsequently, mercury was separated by using filter paper. The mercury oxide amount contained in the filtrate was quantitatively analyzed by an atomic absorption spectrometry. Mercury left on the filter was dissolved in nitric acid, and its amount was also obtained by the atomic absorption spectrometry. This method gave the correct amount of mercury oxide. It was difficult, however, to distinguish the mercury amount adsorbed on the phosphor from that of free mercury, and the mercury amount obtained might be larger than that of the adsorbed mercury.

\section{Experimental Results}

3.1 Phosphor charging tendency and lamp luminous flux ratio

Fig. 4 shows the luminous flux ratio as a function of lighting time of lamps coated with $\mathrm{Y}_{2} \mathrm{O}_{3}$ : Eu phosphors. After 100 hour operation, decrease in luminous flux ratio is small with a phosphor having positive charging tendency $(+0.31 \mu \mathrm{C} / \mathrm{g})$, and it is large with phosphors having negative charging tendency $(-0.50 \mu \mathrm{C} / \mathrm{g}$ and $-1.44 \mu \mathrm{C} / \mathrm{g})$.

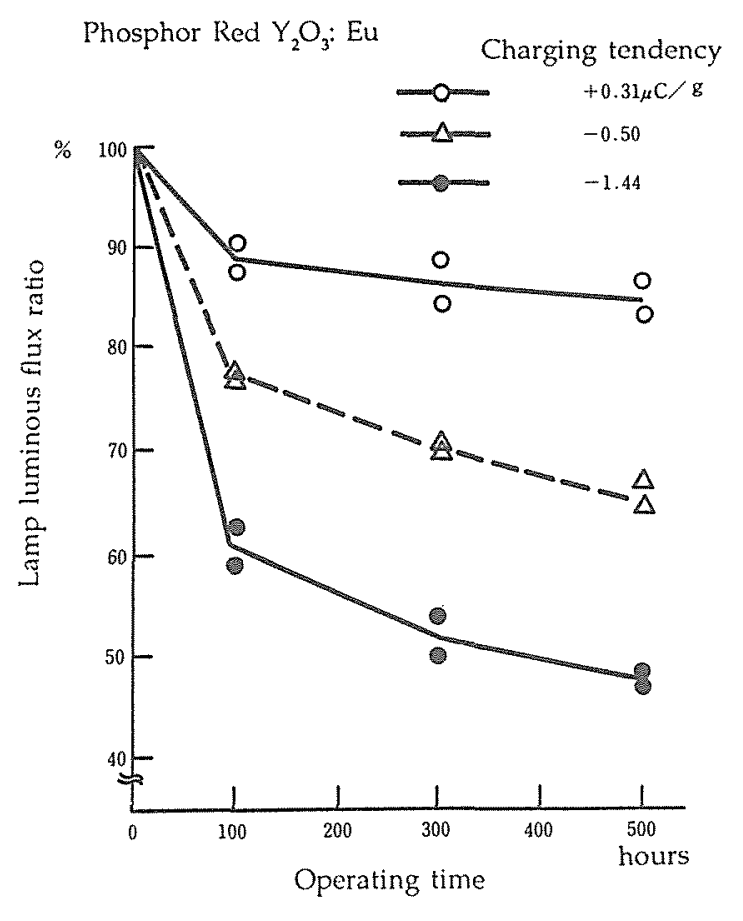

Fig. 4 Luminous flux ratio and lamp operation time.

Fig. 5-1 to 5-4 show the luminous flux ratio after 300 hours of operation compared with that at 0 hours of operation as functions of phosphor charging tendency. 


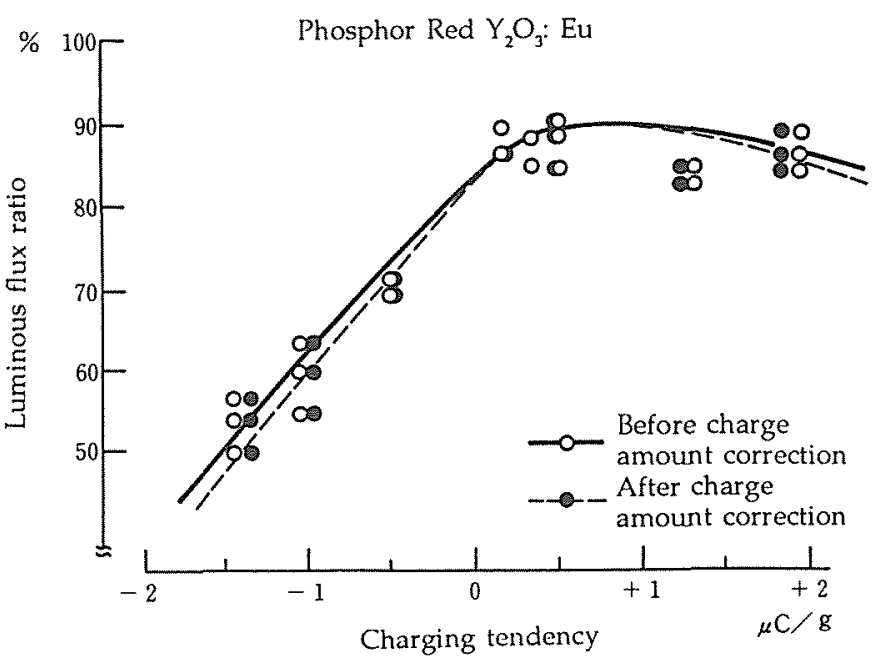

Fig. 5-1 Phosphor charging tendency and lamp luminous flux ratios

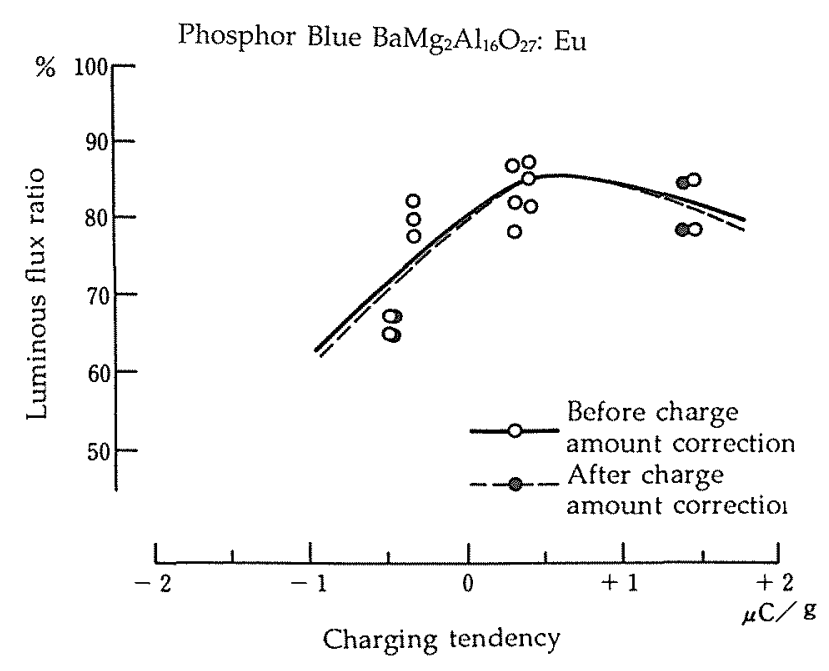

Fig. 5-3 Phosphor charging tendency and lamp luminous flux ratios

Figure 5-1 is the case where $\mathrm{Y}_{2} \mathrm{O}_{3}$ : Eu was used Fig. 5-2 $\mathrm{La}(\mathrm{P}, \mathrm{Si}) \mathrm{O}_{4}: \mathrm{Ce}, \mathrm{Tb}$, Fig. 5-3 $\mathrm{BaMg}_{2} \mathrm{Al}_{16} \mathrm{O}_{27}$ : Eu and Fig. 5$4 \mathrm{Zn}_{2} \mathrm{SiO}_{4}: \mathrm{Mn}$.

In the case of $\mathrm{Y}_{2} \mathrm{O}_{3}$ : Eu, the luminous flux ratio depends strongly on the phosphor charging tendency. In the negative charging tendency region it decreases severely as the absolute charge amount becomes larger, and is as small as about $50 \%$ at $-1.5 \mu \mathrm{C} / \mathrm{g}$. In the positive charging tendency region, the luminous flux ratio is larger than that in the negative region. It is above $80 \%$, and there is a maximum peak (about $90 \%$ ) at around $+0.5 \mu \mathrm{C} / \mathrm{g}$.

In case of the other phosphors also, the luminous flux

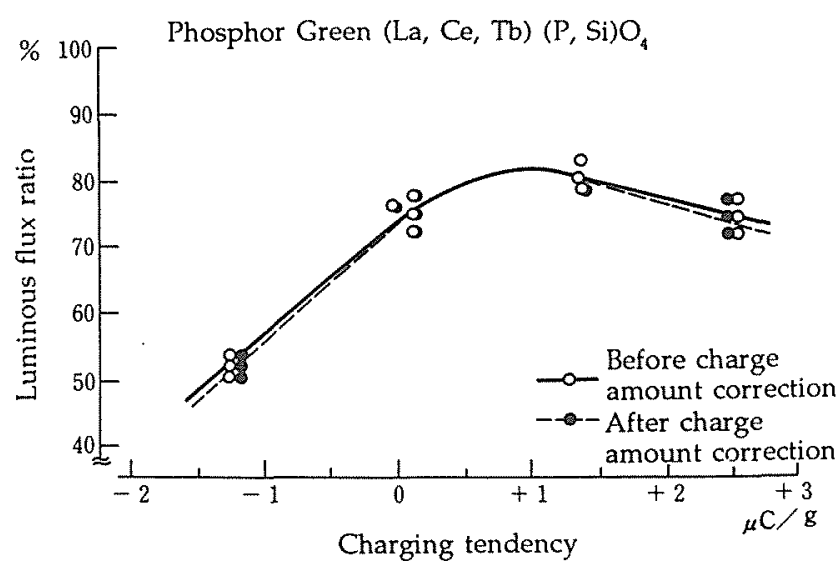

Fig. 5-2 Phosphor charging tendency and lamp luminous flux ratios

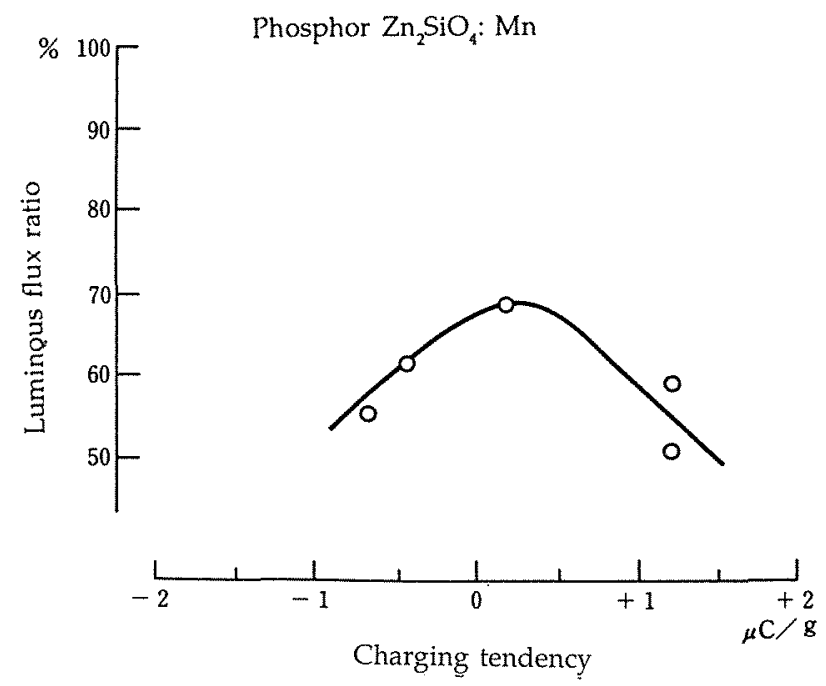

Fig. 5-4 Phosphor charging tendency and lamp luminous flux ratios

ratio depends strongly on the phosphor charging tendency. In every case, a peak appears at around $+0.5 \mu \mathrm{C} /$ $\mathrm{g}$ as observed in the case of $\mathrm{Y}_{2} \mathrm{O}_{3}$ : Eu.

3.2 Relation between phosphor charging tendency and brightness of phosphors scraped out (scraped out phosphor) from a lamp

Fig. 6-1 to 6-3 compare powder brightness ratios of scraped out phosphors after 300 hours of lamp operation. to those of initial phosphors before the coating. In these figures, brightness ratios marked with "a" refer to samples 
obtained by heating at $125^{\circ} \mathrm{C}$ for 30 minutes to remove mercury before brightness measurement, and " $\mathrm{b}$ " refers to samples obtained by, in addition to the above heat treatment, heating at $500^{\circ} \mathrm{C}$ for 60 minutes to remove mercury oxide as well. Figure 6-1 shows the case where $\mathrm{Y}_{2} \mathrm{O}_{3}$ : Eu was used, Fig. 6-2 for $\mathrm{La}(\mathrm{P}, \mathrm{Si}) \mathrm{O}_{4}$ : $\mathrm{Ce}, \mathrm{Tb}$ and Fig. 6-3 for $\mathrm{BaMg}_{2} \mathrm{Al}_{16} \mathrm{O}_{27}$.

After removal of both mercury and mercury oxide, the brightness ratio is recovered to about $95 \%$ in the case of red-emitting phosphor, 70 to $90 \%$ in the green and about $75 \%$ in the blue. These results show that degradation of

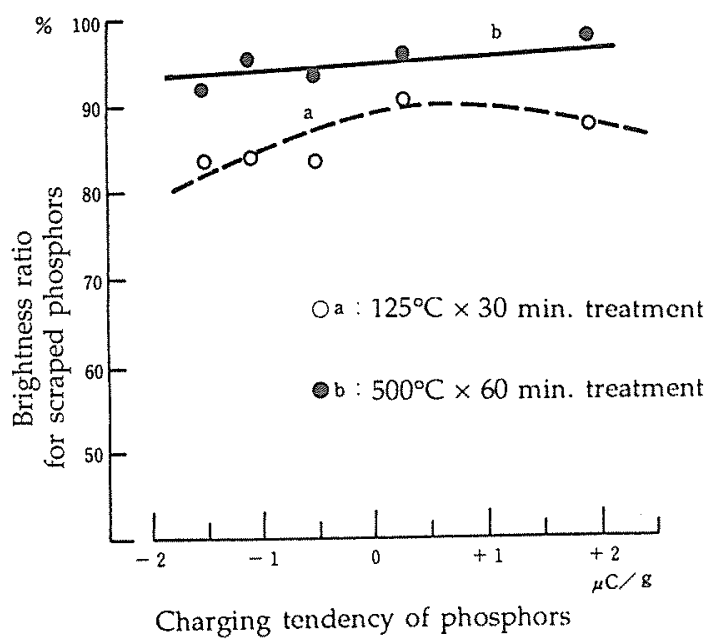

Fig. 6-1 Phosphor $\left(\mathrm{Y}_{2} \mathrm{O}_{3}\right.$ : Eu) charging tendency and brightness ratios for scraped out phosphors. A brightness ratio means relative brightness value for a scraped phosphor compared with brightness for the phosphor before lamp coating.

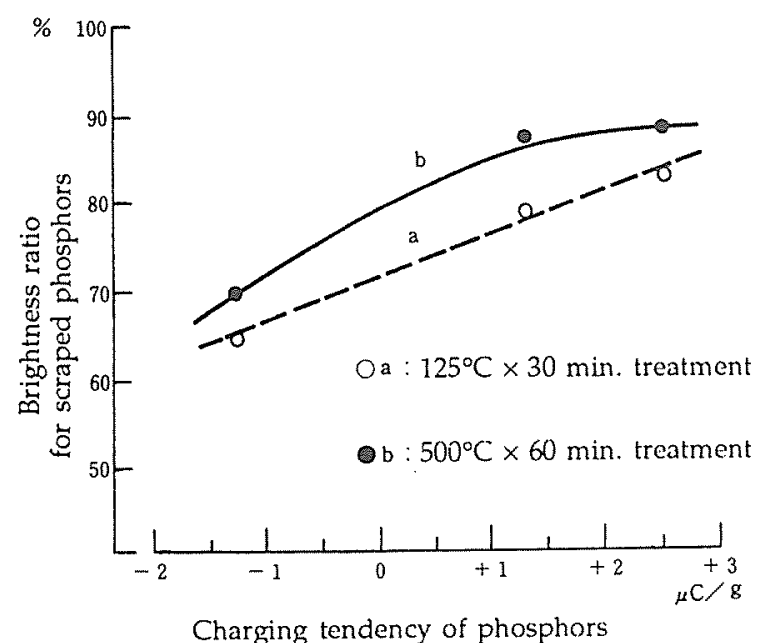

Fig. 6-2 Phosphor ((La, Ce, Tb) (P, Si) $\left.\mathrm{O}_{4}\right)$ charging tendency and brightness ratios for scraped out phosphors.

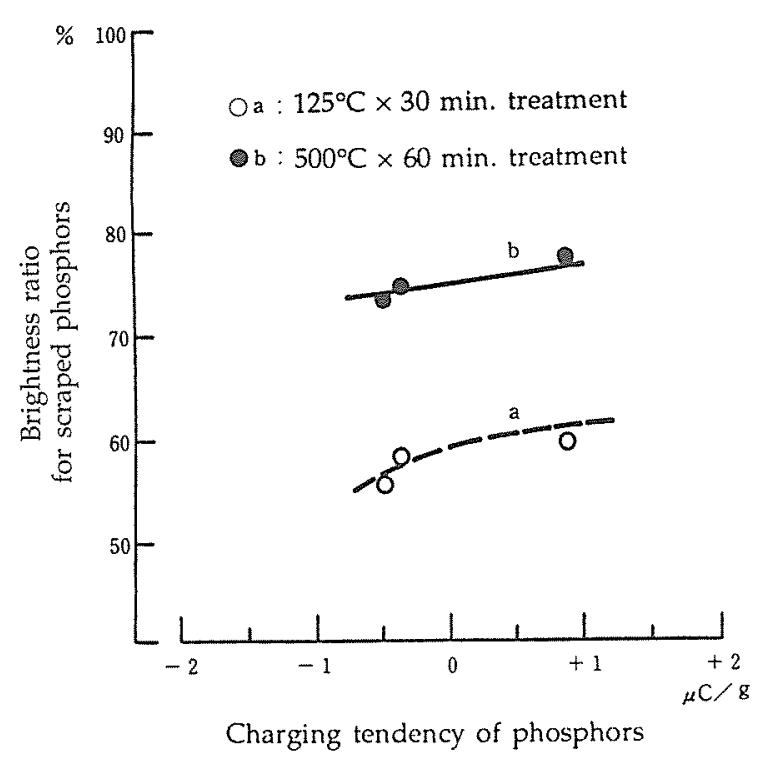

Fig. 6-3 Phosphor $\left(\mathrm{BaMg}_{2} \mathrm{Al}_{16} \mathrm{O}_{27}: \mathrm{Eu}\right)$ charging tendency and brightness ratios for scraped out phosphors.

phosphors themselves is small in the red-emitting phosphor. The small brightness ratios in the blue-emitting phosphor might result from the phosphor degradation during mercury oxide removing process ${ }^{14)}$. The brightness ratio of scraped out phosphors after removing mercury and mercury oxide depends little on phosphor charging tendency. In other words, degradation of phosphors themselves depends hardly on their charging tendency. Within the present experimental range of charging tendency, difference in the brightness ratio between the maximum and minimum for samples after removing mercury and mercury oxide is $5 \%$ for the red, $18 \%$ for the green and $5 \%$ for the blue. These values are much smaller than the difference between the maximum and minimum values in the lamp luminous flux ratio $(40 \%, 30 \%$ and $30 \%$, respectively), which contrarily shows that the influence of adsorbed mercury and mercury oxide on lamp depreciation is great.

\subsection{Phosphor charging tendency and mercury adsorption amount on phosphors}

Fig. 7 shows the amounts of mercury and mercury oxide adsorbed on red-emitting $\mathrm{Y}_{2} \mathrm{O}_{3}$ : Eu phosphors obtained from lamps after 300 hours of operation as a function of phosphor charging tendency. The mercury oxide amount depends strongly on the charging tendency. As the charging tendency goes toward negative direction it increases rapidly, but it is small and almost constant in positive charging tendency region. The ratio of the maximum amount to the minimum reaches as high a 
value as 20 . The curve shape representing the relation between the mercury oxide amount and charging tendency in Fig. 7 is anti-symmetric to that between the luminous ratio and charging tendency in Fig. 5-1. The mercury amount adsorbed on phosphors, on the other hand, shows small dependence on the charging tendency, and it is almost constant over the whole charging tendency region.
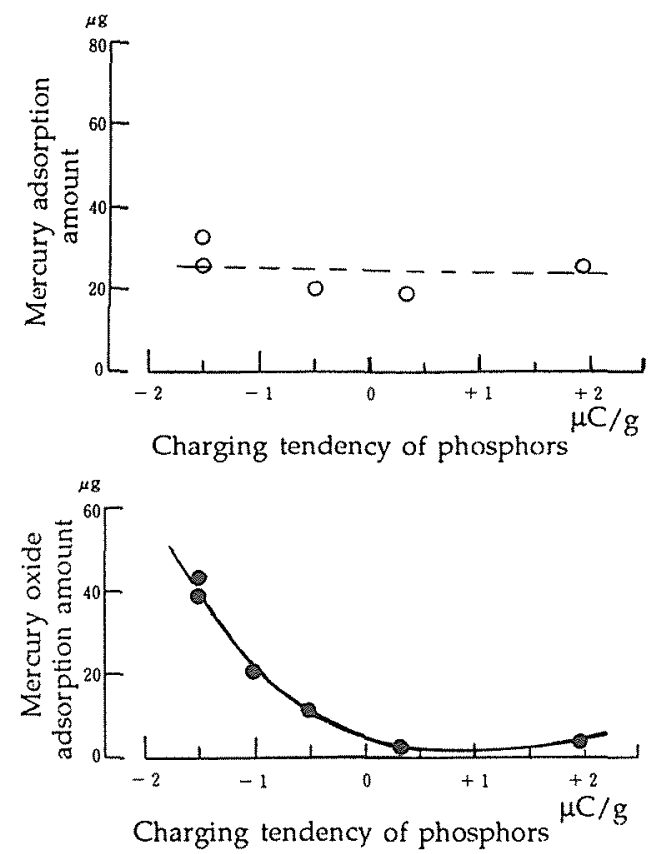

Fig. 7 Phosphor charging tendency and adsorption amount of mercury and mercury oxide on phosphors in lamps.

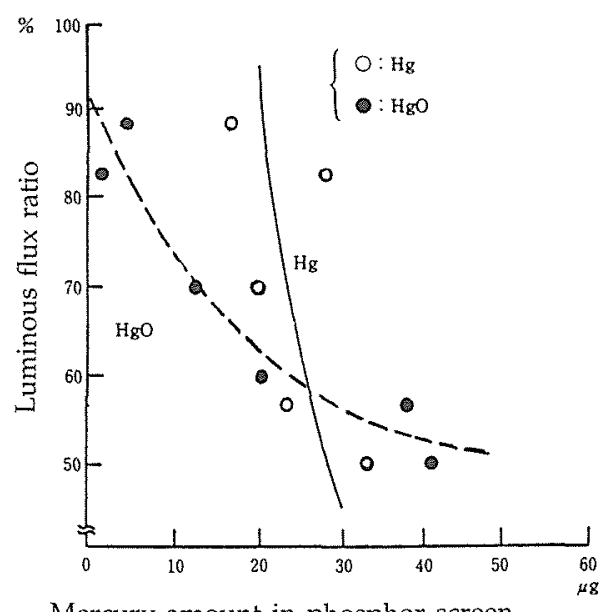

Mercury amount in phosphor screen

Fig. 8 Mercury and mercury oxide adsorption amount in phosphor layers $\left(\mathrm{Y}_{2} \mathrm{O}_{3}\right.$ : $\left.\mathrm{Eu}\right)$ and luminous flux ratios.
Fig. 8 shows the luminous flux ratio as functions of mercury and mercury oxide amounts adsorbed on phosphors. The luminous flux ratio decreases severely with increase in the mercury oxide amount. On the contrary, the amount of adsorbed mercury is almost constant within 20 to $40 \mu \mathrm{g}$, and is not well correlated to the luminous flux ratio. These results show that decrease in luminous flux ratio is governed by mercury oxide adsorption rather than by mercury adsorption.

\section{Discussions}

\subsection{Influence of phosphor surface area on charging tendency}

In the present paper, phosphor charging tendency has been expressed hitherto as the charge amount per $1 \mathrm{~g}$ phosphor which is generated in contact with a reference iron powder. When adsorption of fine particles or gas is considered, however, it may be more adequate to compare charging tendencies by using the charge amount per unit surface area of a phosphor. In the present study, the phosphor particle size has been obtained with the air permeability method ${ }^{13)}$. In this method air permeability through a powder filled layer gives a specific surface area, from which particle size is calculated assuming every particle to have a spherical shape. Apparent particle size of a colloid deposited phosphor obtained by this method, therefore, decreases because of increase in specific surface area. To cope with this, product of the charge amount per unit weight and apparent particle size was calculated for every sample in a phosphor system, and normalized to that for non-colloid treated one. This procedure may correct the charging tendency into a value in proportion to the charge amount per unit surface area. Luminous flux ratios were re-plotted as functions of the corrected charging tendency, and results are shown in Figs. 5-1 to 5-3. After the correction, such significant facts as that the luminous flux ratio decreases severely in the negative charging tendency region and that it has a maximum value at a certain position in the positive charging tendency remain the same as those before the correction.

\subsection{Charging tendency positions of phosphors and blackened materials $(\mathrm{HgO})$}

In Sections 3-1 to 3-3, luminous flux ratio and the adsorbed amount of blackened materials (especially mercury oxide) were shown to depend strongly on phosphor charging tendency and to have maximum and minimum values, respectively, at a certain value of the charging tendency. These facts may be explained assuming a mechanism as follows. In the case of large difference in charging tendency between a phosphor and a blackened material, contact of them produces a large amount of electric charges at their interface. Intensive electrostatic attractive force exerts between them, making 
the blackened material difficult to desorb. On the contrary, small difference in the charging tendency leads to a small charge amount generated, weak electrostatic attractive force and easy desorption. Therefore, the former case leads to earlier lamp blackening and severer depreciation in luminous flux than the latter case. In other words, the lamp luminous flux is less depreciated as charging tendency of a blackened material is closer to that of a phosphor. To verify this explanation, it is necessary to confirm that mercury oxide lies in charging tendency close to a phosphor with the maximum luminous flux ratio or a phosphor with the minimum mercury oxide adsorption. However, since the charge amount obtained by the blow-off method depends strongly on sample particle sizes, direct comparison of the charge amounts between two samples is meaningless when these samples have different particle sizes as in the case of a phosphor and mercury oxide.

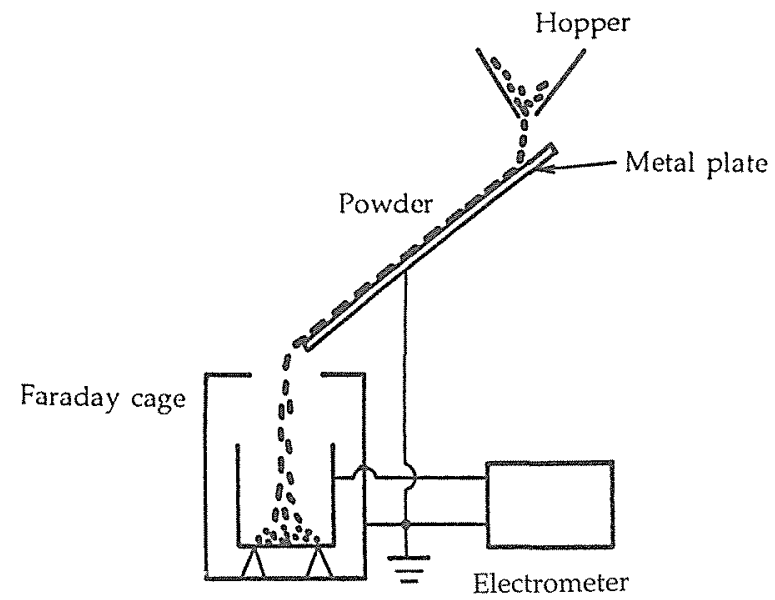

Fig. 9 Cascade-down charge measuring apparatus ${ }^{15)}$.

Then, a method in which relative charging tendency of a sample may be obtained irrespective of its size ${ }^{15)}$ was used to find a position in charging tendency of mercury oxide among phosphors. Fig. 9 outlines the measuring apparatus. The apparatus is so designed that a powder is slid down on the metal plate and that the charge polarity produced by the contact between the powder and the metal plate is detected with an electrometer connected to the Faraday cage. When charging tendency of a number of metal plates is known, charging tendency of a powder sample is determined relatively among these metals. Fig. 10 shows positions in charging tendency for $\mathrm{Y}_{2} \mathrm{O}_{3}$ : Eu phosphors and a reagent $\mathrm{HgO}$ powder, found by this method. $\mathrm{HgO}$ is positioned between $\mathrm{Cr}$ and $\mathrm{Ni}$, or a little higher than $\mathrm{Ni}$, depending on measuring conditions. This position is close to that of the $\mathrm{Y}_{2} \mathrm{O}_{3}$ : Eu phosphor whose particle surfaces were deposited by $0.2 \% \mathrm{MgO}$ colloids. This phosphor shows the charge amount of $+1.9 \mu \mathrm{C} / \mathrm{g}$ against the iron powder in the blow-off method. Taking into account the fact that the measuring method is semiquantitative, it is supposed that the charging tendency position of $\mathrm{HgO}$ represented in the charge amount against the iron powder may contain an error of about $\pm 0.5 \mu \mathrm{C} / \mathrm{g}$.

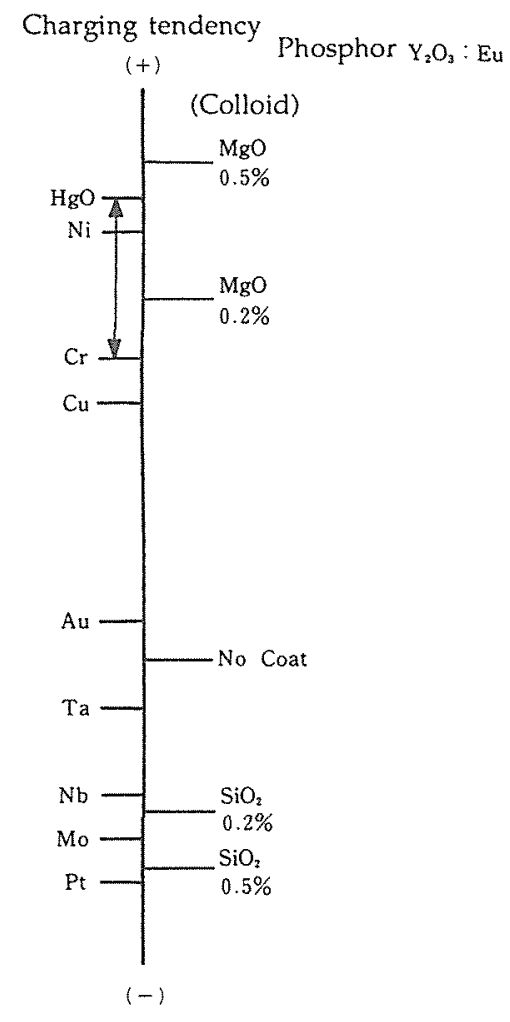

Fig. 10 Charging tendency for phosphors $\left(\mathrm{Y}_{2} \mathrm{O}_{3}\right.$ : $\left.\mathrm{Eu}\right)$ and $\mathrm{HgO}$.

The value of the charging tendency of $\mathrm{HgO}$ found in this way is not in the negative region where the luminous flux ratios severely depreciated (Fig. 5-1) and the mercury oxide amount adsorbed is largely increased (Fig. 7). The value is close to $+0.5 \mu \mathrm{C} / \mathrm{g}$ with maximum luminous flux ratio and to $+2 \mu \mathrm{C} / \mathrm{g}$ with the minimum adsorbed amount. That is, the charging tendency of a phosphor which has the maximum luminous flux ratio and the minimum mercury oxide adsorption amount is positioned close to that of mercury oxide. This confirms the validity of the assumption that the lamp luminous flux is less depreciated as the phosphor is closer to blackened material in charging tendency.

Charging tendency position of $\mathrm{HgO}$ is not completely identical to those of phosphors which give the maximum luminous flux ratio or the minimum amount of mercury oxide adsorbed. The followings are suspected to be the 
causes for it. First, since both the luminous flux ratio and the adsorption amount do not differ greatly from their maximum and minimum values, respectively, in the region between $+0.5 \mu \mathrm{C} / \mathrm{g}$ and $+2 \mu \mathrm{C} / \mathrm{g}$, charging tendency positions for the maximum luminous flux ratio and minimum adsorption are not determined with a high degree of accuracy. Second, since $\mathrm{HgO}$ used for measurements is an orange-colored reagent powder, its charging tendency may not be completely identical to that of black- to brown- colored mercury oxide existing in a lamp. Further study will be needed to clarify these points.

\section{Conclusion}

Depreciation in luminous flux in high-load fluorescent lamps was studied using 3-band phosphors. After longterm operation, Iuminous flux decrease of lamps, powder brightness of scraped out phosphors, and adsorption amounts of mercury and mercury oxide were investigated by varying charging tendency of phosphors systematically with surface treatments of colloid deposition. It turned out from the investigation that the luminous flux depreciation and adsorption amount depended strongly on phosphor charging tendency in every phosphor system tested. It was also found that the degradation of phosphors themselves did not depend on the charging tendency, and that luminous flux depreciation was governed by mercury oxide adsorption rather than by mercury. In addition, phosphors with the maximum luminous flux ratio and with the minimum mercury oxide adsorption were located in charging tendency close tomercury oxide.

From these results, it was concluded that the adsorption amount of mercury oxide depended on difference in charging tendency between a phosphor and mercury oxide, and that a large part of lumen maintenance was governed by phosphor charging tendency. For phosphors which have undergone no surface treatments also, it is inferred that factors governing the lamp lumen maintenance include the mechanism of mercury oxide adsorption due to the difference in phosphor charging tendency, in addition to degradation of phosphors themselves.

\section{Acknowledgments}

The authors wish to express sincere thanks to Dr. T. Oguchi, Recording Media Division of Toshiba Corporation, for his helpful suggestions concerning charging tendency measurements using the cascade method, and Mr. S. Naoki, Research and Development Center of Toshiba Lighting \& Technology Corporation, for performing measurements using the above method.

\section{References}

(1) Apple, E.F.: "Observations on the formation of color centers in calcium halophosphates" J. Electrochem. Soc. 110-5 (1963) 374

(2) Phosphor Handbook ed. by Phosphor Research Society (1987) 205 OHM Publishing Company (in Japanese)

(3) Kimura, Narita, Terashima: "Rare earth phosphors for three-band type fluorescent lamps" Toshiba Review 37-2 (1982) 110-113 (in Japanese)

(4) Ito, Terashima: "Surface charging amount on fluorescent phosphors and luminous flux maintenance" Proc. 1990 Annual Conf. IEI Japan, Abstr. 12 (in Japanese)

(5) Higashikawa, Shinomiya: "Investigations of causes of luminous flux decrease in electrodeless fluorescent lamps" Proc. 1991 Annual Conf. IEI Japan, Abstr. 11 (in Japanese)

(6) Kawabata, Taguchi, Kondou, Moriwaki, Azuma, Iwama: "Application of titanium oxide film to fluorescent lamps" Proc. 1991 Annual Conf. IEI Japan, Abstr. 14 (in Japanese)

(7) Verhees, P.W.C.: "Mercury consumption in fluorescent lamps" Proc. 5th International Symposium of Light Sources (1989) 105L

(8) Oguchi, Tamatani: "Contact electrification in organic and inorganic powders" J. Electrostatics Soc. Japan, 7-5 (1983) 292 (in Japanese)

(9) Oguchi, T., Tamatani, M.: "Contact electrification in inorganic binary compounds" J. Electrochem. Soc. 133-4 (1986) 841

(10) Tamatani, M., Oguchi, T.: "Contact electrification of inorganic phosphors" Extended Abstracts of the 161st Electrochem. Soc. Meeting, Montreal (1982) 798

(11) Ito, Taya, Tamatani, Terashima: "Phosphor charging tendency for fluorescent lamps and their life performance" Proc. 233rd Phosphor Research Society Meeting (1990) 17-26 (in Japanese)

(12) Edited by Chem.Soc. Jpn: "Kagaku Binran (Chemistry Handbook)" Maruzen (1984) (in Japanese)

(13) Edited by Kubo, Suito, Nakagawa, Hayakawa: "Huntai (Powders)", Maruzen (1962) 161-172 (in Japanese)

(14) Narita: "Relative quantum efficiency of various lamp phosphors" J. Illum. Engng. Inst. Jpn. 69-2 (1985) 65 (in Japanese)

(15) Oguchi, Tamatani: "Contact electrification of powders and its application" Oyo Butsuri (Applied Physics) 52-8 (1983) 674 (in Japanese) 